\title{
ANTIBODIES IN FALCIPARUM MALARIA: WHAT MATTERS MOST, QUANTITY OR QUALITY?
}

\author{
HASNAA BOUHAROUN-TAYOUN \& PIERRE DRUILHE
}

Laboratoire de Parasitologie Medicale, Institut Pasteur, 28, rue du Dr Roux, 75015 Paris, France

In view of the recent demonstration that antibodies that are protective against Plasmodium falciparum malaria may act in collaboration with blood monocytes, we have investigated the isotype content of sera from individuals with defined clinical states of resistance or susceptibility 10 malaria. Profound differences in the distribution of each Ig subclass and particularly in the ratio of cytophilic versus noncytophilic antibodies were found. In protected subjects, two cytophilic isotypes, IgGI and IgG3 were found to predominate. In non-protected subjects, i.e. children and primary attack adults, three different situations were encountered: a) an imbalance in which IgG2, a non-cytophilic class, predominated (mostly seen in primary attacks); b) an imbalance in which mostly IgM antibodies predominated (a frequent event in children) or c) less frequently, an overall low level of antimalarial antibodies. Of 33 non immune subjects studied all, except one, had one of the above defects.

The function of total Ig presenting such an isotype imbalance was studied in vitro in AntibodyDependent-Cellular-Inhibition assays. Not only did $\operatorname{Ig} G$ from protected subjects cooperate efficiently with blood monocytes, whilst IgG from non-protected groups did not, but moreover the latter inhibit the in vitro effect of the former: in competition assays whole Ig $G$ from primary attack cases with increased $\operatorname{IgG2}$ content, competed with $\operatorname{IgG}$ from immune adults, thus suggesting that nonprotected subjects had antibodies to epitopes critical for protection, but that these antibodies are non functional.

Key words: Plasmodium falciparum - protective immunity - immune response - immunoglobulin - isotypes

Several decades of clinical studies on Plasmodium falciparum malaria have shown how special is the type of immune resistance which develops in humans (Ciuca et al., 1934; Daniels, 1901; Redmond, 1941). Numerous surveys in hyper or holoendemic areas have established that the pathology by the parasite is almost absent from adults who harbour only very low level parasitemia. Acquired anti-parasite immunity has thus been coined "premunition" to reflect the fact that it is an incomplete, non sterilizing immunity, which is acquired extremely progressively (Sergen \& Parrot, 1935). Such protection rely in great part upon antibodies of IgG class as showed by the in vivo effect in humans of passively transferred African adult's IgG (Gohen et al., 1961; Edozien et al., 1962; McGregor et al., 1963; Sabchareon et al., 1991).

Our previous in-vitro studies led us to the idea that naturally occurring antibodies may by themselves be unable to directly limit parasite growth and caused us to suspect that such antibodies would rather be acting indirectly by stimulating blood monocytes through the FC receptors after binding to their parasite target (Kusmith \& Druilhe 1983; Lunel \& Druilhe, 1989 and unpublished data). This hypothesis was recently strengthened by the results of a comparative in-vivo/in-vitro analysis (Bouharoun-Tayoun et al., 1990) where the antibodies which proved protective in-vivo by passive transfer of immune Ig in humans, had no effect in-vitro on the growth of $P$. falciparum asexual blood stages unless they were allowed to cooperate with blood monocytes. Conversely, antibodies which were not protective in-vivo were unable to exert in-vitro an antimalarial effect by cooperation with monocytes.

In the context for such an indirect monocyte-dependent effect of antibodies, the subclasses of antibodies produced in response to 
infection, are of particular importance, since certain isotypes such as $\mathrm{IgG} 2$ and $\mathrm{IgM}$, being non-cytophilic, are unable to specifically arm monocytes.

We thus investigated the isotype distribution in sera from protected versus non protected individuals. The possibility that antibodies exhibiting a different isotype pattern may be directed to the same target epitopes was in addition investigated in-vitro by means of competition assays.

\section{RESULTS}

In view of the possibility that antibodies act in cooperation with blood monocytes (Bouharoun-Tayoun et al., 1990) we investigated in in vitro conditions, using the ADCI assay, the effect of IgG from 10 Primary attack (PA) cases (i.e. European adults experiencing their first $P$. falciparum infection, sera being collected 1022 days after the attack), in comparison with ten individual Hyperimmune (HI) sera (i.e. from African adults living in a hyperendemic region). Results showed clearly that in the presence of blood monocytes IgG from all PA cases were found unable to promote a monocyte inhibitory effect of $P$. falciparum multiplication, while IgG from African adults (HI) yelded consistently a significant inhibitory effect on growth (Fig. 1).

By western blot revealed with class specific second antibodies, we compared the isotypic pattern of the humoral immune response to $P$. falciparum antigens in the same 20 individuals. To enable an estimate of the relative amounts of antibodies of each subclass the autoradiographs were scanned and the area under the curves measured. Although such results may not express the total amount in a given isotype they however allow a comparative study of isotypes produced by individuals with different clinical status within a given experiment. An example of results obtained with six individual sera are shown in Fig. 2. Although the relative proportions of antibodies of each isotype varied from one individual to another, and within the assay conditions, we found that the levels of IgG3 antibodies were consistently elevated in each of the African immune adults, whilst $\operatorname{IgG} 2$ antibody levels were relatively low. IgG3 production represented $69.7 \pm 51.7 \%$ (mean \pm SD) of the amount of IgG1 antibodies and IgG2 $53.9 \pm 35.6 \%$ of IgGl (three examples are shown in Fig. 2). In the series of ten Europeans

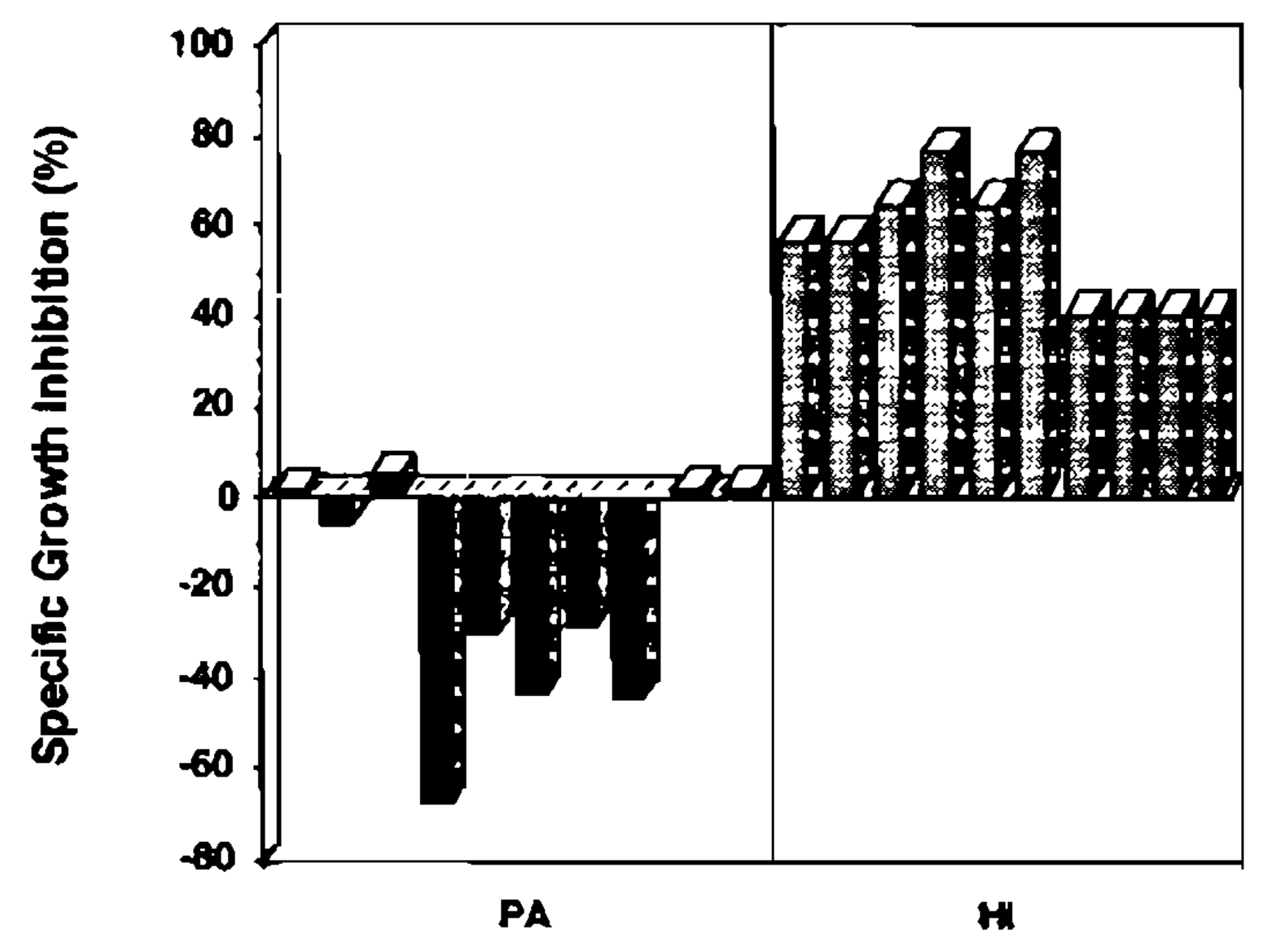

Fig. 1: effect on purified lgG's from ten Primary Attack patients (PA) (solid bars) and from ten Hyperimmune individuals (HI) (hatched bars) in an Antibody Dependent Cellular Inhibition (ADCI) assay. IgG were purified by ion exchange chromatography on DEAE cellulose (IBF, Villeneuve-La-Garenne, France); 48 h cultures were performed using the Plasmodium falciparum strain NF54 in the presence of monocytes freshly isolated from a normal blood donor (Bóyum, 1968), and the $\mathrm{gg}$ fraction to be tested at $10 \%$ of its concentration in the donor's serum. Controls consisted of cultures in the presence of a) normal $\operatorname{IgG}$, b) test $\operatorname{Ig} G$ alone, c) monocytes plus normal IgG. Parasitemia was determined by microscopic examination of $>10,000$ erythrocytes. Results are expressed as the Specific Growth Inhibitory index (SGl) calculated as follows:

SGl $=100 \times[1-$ (percent parasitemia with monocyte and $\mathrm{IgG} /$ percent parasitemia with IgG)/(percent parasitemia with monocyte and control $1 \mathrm{gG} /$ percent parasitemia with control $\mathrm{IgG}$ )].

(A negative SGI represents an increase of parasite growth as compared to controls).

recovering from a primary attack more diverse situations were encountered. Some individuals simply had an overall low response in each subclass but particularly in IgG3 and IgG4 (not shown). Four individuals had high to very high levels of antimalarial antibodies but with relatively low IgG3 levels compared to the African and elevated responses in the $\mathrm{IgG} 2$ isotype as compared to African adults and to their own IgG3 content. IgG2 represented on the average $88 \pm 70 \%$ of the IgG1 content and IgG3 only $38 \pm 39 \%$ of IgG1. In this series, IgM antibodies were low in eight of the ten cases (not shown). In the two cases in whom IgM antibodies were found, this was associated with elevated IgG2 antibody levels.

These results led us to hypothesise that the absence of protection observed after a single infection as well as the absence of effect in 
TABLE

Competition $\mathrm{ADCl}$ assay

\begin{tabular}{|c|c|c|c|}
\hline & \multicolumn{2}{|c|}{ IgG used in the ADCI assay } & \multirow[b]{2}{*}{ Specific Growth Inhibition (\%) } \\
\hline & source & concentration $(\mathrm{mg} / \mathrm{ml})$ & \\
\hline \multirow{4}{*}{ 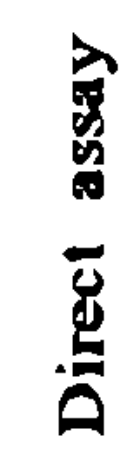 } & PIAG & 2.5 & 60 \\
\hline & HI & 2.5 & 65 \\
\hline & PAl & 1.2 & 3 \\
\hline & PA2 & 1.2 & 0 \\
\hline \multirow{8}{*}{ 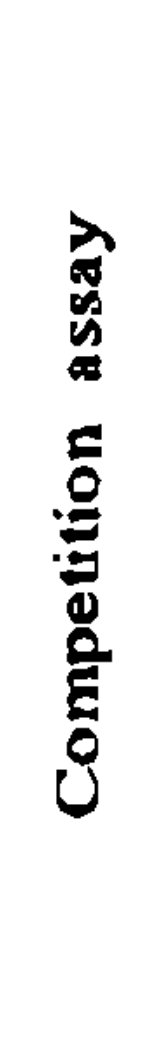 } & PA1 & 1.2 & 20 \\
\hline & + PIAG & 2.5 & \\
\hline & PA2 & 1.2 & 5 \\
\hline & + PIAG & 2.5 & \\
\hline & $\mathrm{N}$ & 2.5 & 60 \\
\hline & + PIAG & 2.5 & \\
\hline & $\mathrm{HI}$ & 2.5 & 66 \\
\hline & + PIAG & 2.5 & \\
\hline
\end{tabular}

The Table showns the SGI recorded when IgG from a Primary Attack (PA) case, a Hyperimmune (HI) individual or a normal individual $(N)$ are allowed to compete with a Pool of Immune African $\lg G$ (PIAG) in the ADCI assay (Competition assay) "Direct assay" indicates the ADCl performed with only one calegory of IgG (PA, individuals $\mathrm{HI}$ or a pool of $\mathrm{HI}=\mathrm{PIAG}$ ). Note that the $\mathrm{IgG}$ concentration for each category is the same in the direct and the competition assay.

ADCI, may result both, not from an absence of immune response to those antigens targeted by a protective immunity, but rather from an $a b-$ normal immune response to those antigens, made in great part of non-cytophilic antibodies.

Competition assays were performed so as to evaluate the possibility that the higher proportion of non-cytophilic antibodies in PA sera may interfere with the function of cytophilic antibodies in Hyperimmune (HI) individuals. It was found that the ability of $\mathrm{IgG}$ from $\mathrm{HI}$ individuals to promote a monocyte-derived inhibitory effect was markedly decreased when IgG from primary attack subjects with high antibody content was also added in the ADCI assay (four of the ten cases studied). No such competitive effect was found when using control IgG from non malarious subjects, or when $\mathrm{IgG}$ from various $\mathrm{HI}$ subjects was added to the positive HI control (Table) nor when using IgG from one PA case who had a particularly low amount of antimalarial antibodies (not shown).

We thereafter studied the isotype distribution in various age groups of subjects from a village of the African savanna in Burkina Faso because African children living in malaria hyper and holoendemic areas remain susceptible to malaria infection, with occurrence of high parasitemias and symptoms, usually up to the age of about 15 years, and develop a resistance by about the age of 15 to 20 years.

The patterns obtained proved to be complex and more diverse than in the preceeding group of patients studied, with high levels of all classes of antibodies being found in many children. However, when compared to adults from the same village, increased levels of either the IgG2 or more frequently the IgM isotype were almost always found in these children. The results obtained in western blots were scanned, the areas under the curve measured and the ratio of the two cytophilic isotypes IgG1 and 3 to the remaining non cytophilic IgG2, 4, and IgM isotypes calculated. Fig. 3 shows that there is a clear-cut difference in this ratio between children and adults. The ratio is below 1, that is a majority of non-cytophilic antibodies in the non-protected children, and above 1 in the protected adults who have a majority of cytophilic antibodies. Surprisingly, the pattern of evolution does not show a progressive modification of these ratios from adolescence to adult age but rather an abrupt switch in the Ig classes expressed above the age of 20 

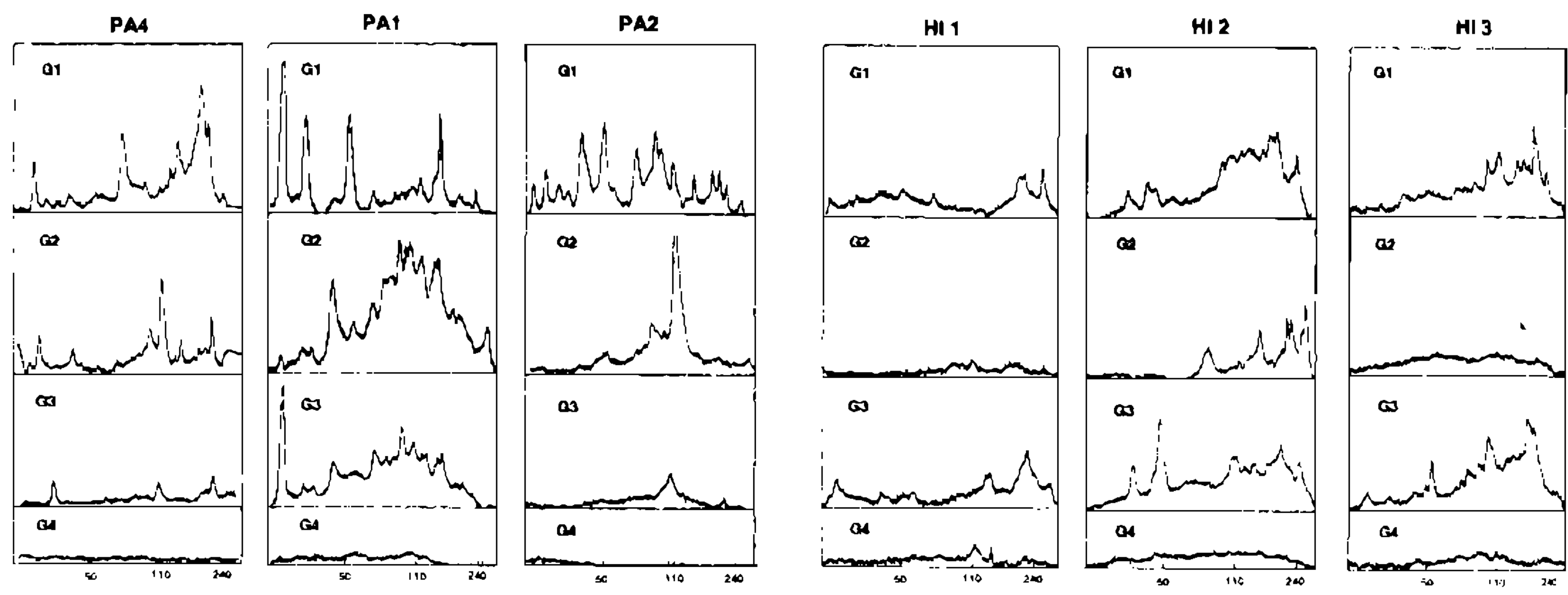

Fig. 2: analysis of IgG subclass distribution in Primary Attack (PA) sera and in Hyperimmune (HI) sera. Western blots were performed using extracts of Plasmodium falciparum NF54 strain as antigen. Mouse monoclonal antibodies (mAb) directed to Human IgG1 (G1: mAb NL16 diluted 1/1000), IgG2 (G2: mAb HP6002 diluted J/5000), IgG3 (G3: mAb ZG4 diluted 1/5000), IgG4 (G4: mAb GB7B diluted 1/15000). The mAbs N116, ZG4 and GB7B were purhased from Unipath (Bedford, UK); mAb HP6002 was a gift from Dr R.G. Hamilton (Baltimore, USA). The choice of the mAbs was based (I) on the results of an international meeting (Jefferis et al., 1985), (II) on the results we obtained with defined Human myeloma proteins and (III) on results conceming their ability to recognize equally well the corresponding isotype in sera from Caucasians, Asians and Negroes. Following incubation with ${ }^{125}$ I-anti mouse antibodies, the nitrocellulose strips were autoradiographed and each strip was scanned with a scanning densitometer (GS300 Hoefer Scientific Instruments, San Francisco, USA). All results presented above were obtained on a single gel. The graphs shows the molecular weight range in the abscissa ( $\times 10^{3}$ daltons) and for each IgG subclass the density of a given band in the ordinate (OD value).

years. A decrease in these ratios is observed when comparing children below and above 5 years this difference lying mainly in the fact that antimalarial IgG2 levels were low under the age of 5 , an expected finding since this subclass is known to be produced only at very low levels in younger children (Morell et al., 1972). In the adults, IgGl was, as before, the main isotype produced.

\section{DISCUSSION}

Previous studies have emphasized the critical role of antibody-cell cooperation mechanisms in defense against the blood stages of $P$. falciparum (Kusmith \& Druilhe 1983; Lunel \& Druilhe 1989; Bouharoun-Tayoun et al., 1990).

We, and others, have previously observed that the quantity of antibody produced by malaria exposed subjects was not predictive in terms of protection (Druilhe \& Kusmith, 1987; Marsh et al., 1989). Despite the presence of high levels of antimalarial antibodies some individuals can develop a rising parasitemia accompanied by symptoms. Such antibodies from non-protected individuals were shown unable to cooperate in-vitro with monocytes. In contrast, antibodies developed by individu- als who had reached a state of protection were not found to be quantitatively more abundant, however could confer protection when transferred passively, and furthermore when tested in-vitro were found able to promote an antibody-dependent cellular inhibition. Finally the western blot patterns of antigens recognized by these two groups of protected and non protected subjects did not, at first glance, show any major qualitative differences which may be responsible for the differing in-vivo and invitro effects of these antibodies.

In view of the possibility that antibodies may act in cooperation with blood monocytes we decided to study the relative proportion of cytophilic to non cytophilic antibodies. The distribution of isotypes produced differed clearly between the group of immune and the group of non-immune subjects. Moreover, it correlated, in almost all the cases studied, with the ability of their Ig to promote and ADCI effect. Seven of the eight protected adults had a majority of either IgG1 or IgG3, two cytophilic isotypes. The children and primary attack adults had either a) an imbalance in which IgG2 predominated, b) an imbalance in which mostly IgM antibodies predominated, c) or an overall low level of antimalarial antibodies. Of the non 


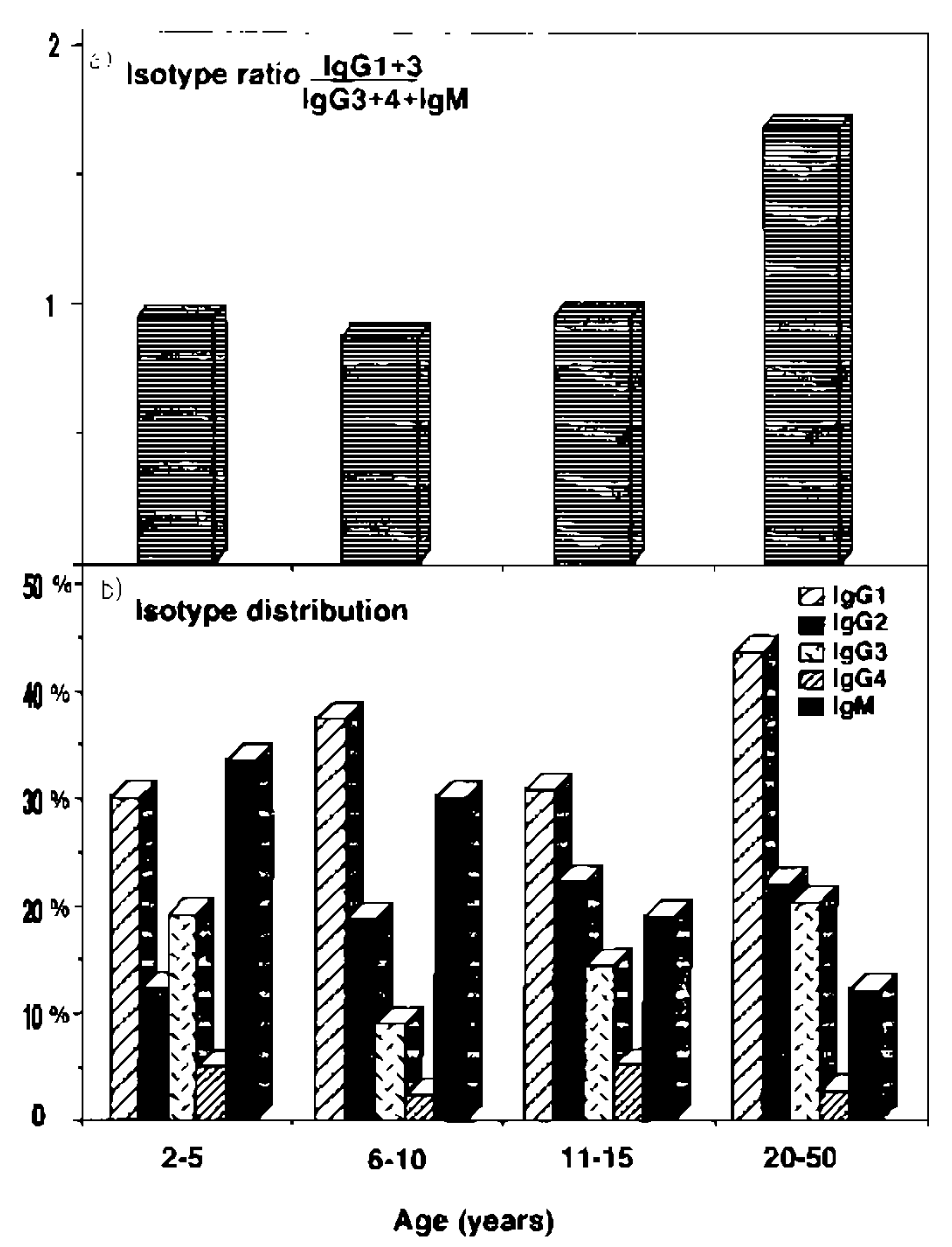

Fig. 3: distribution of cytophilic and non cytophilic anli malarial antibodies in African subjects of different age group. Autoradiogaphs of western blots revealing IgGI, $2,3,4$ and IgM class of anti $P$. falciparum antibodies from each individual were performed and scanned as described in Fig. 2 and the area under the curve measured in a) ratio of the cytophilic $(\mathrm{IgGi}+3)$ to the non cytophilic isotypes $(\operatorname{Ig} C 2+4+\operatorname{IgM})$; shown are the geometric mean of the different ratios recorded in 7 children aged 2-5 years, 7 children aged 6-10 years, 8 aged $11-15$ and 8 adults (20-50). In b) is shown, for the same individuals, the geometric mean of the amount of each isotype expressed in percentage of the total anti malarial antibody response.

immune subjects studied all, except one, had one of the above defect. Only one, out of a total of 32 individuals ( 22 children, 10 PA) had an isotype pattern similar to that of protected adults.

This pattern of distribution of antimalarial antibodies is in agreement with previous reports. An isotype imbalance was previously described in Swedish PA cases when compared to HI African adults from Liberia (Wahlgren et al., 1983): Antimalarial antibodies of various specificities were detected by ELISA, using a whole $P$. falciparum extract as antigen. Increased IgG2 levels were found in many PA cases, and increased $\lg G 3$ in many African protected subjects. In a further series the same authors (Wahlgren et al., 1986) reported a high prevalence of IgM antibodies in African children aged 2 to 15 years.

These findings along with our results can now be interpreted in the perspective of a defense mechanism which requires monocytes and those antibodies able to attach to them via their Fc receptors, namely $\operatorname{IgGl}$ and $\mathrm{IgG3}$, and of the possible blocking effect of the non cytophilic classes, namely $\operatorname{IgG} 2, \operatorname{IgM}$ and possibly IgG4. When we attempted to correlate the isotype distribution observed with the biological function of those $\mathrm{Ig}$ in the monocyte-Ig cooperation assay termed ADCI, using whole IgG preparations, very clear-cut results were obtained: (I) in direct ADCI assays none of the IgG preparations from PA cases having either and IgG2 imbalance or low antibody titers could promote an ADCI effect; in contrast all HI IgG's in whom the imbalance was in favour of IgGl and IgG3 showed a positive ADCI; (II) in competition ADCI assays, whole IgG from PA subjects with increased IgG2 content, competed with HI IgG's, blocking or reducing their ADCI promoting activity.

These results lead us to raise the hypothesis that the progressive development of a state of protective immunity may in fact correspond to a progressive modification in the immune response regulation and not, as has been thought for a long time, to the slow development of a response to either poorly immunogenic, or highly polymorphic molecules. The acquisition of a state of resistance appears to correlate with the ability to develop antibodies of the proper isotype (mostly IgG3 and also IgG1) and to reduce the proportion of non-cytophilic isotypes (IgG2 and IgM) of the same specificity which exhibit a blocking effect on the effector mechanisms.

Cooperation between monocytes and antibodies would appear to be an essential effector mechanism in the acquired state of protective immunity, though others can be involved. It is also clear that the production of non-cytophilic classes would not be the sole means of escape induced by the parasite. Our findings nevertheless modify the perspective in which immunity to malaria and "protective antibodies" should now be envisaged. They clearly stress the need to investigate immune responses in qualitative terms and not only in terms of quantity directed to a given antigenic specificity, consequently they have major implications and open new arcas of research for vaccine development. 


\section{REFERENCES}

BOUHAROUN-TA YOUN, H.: ATTANATH, P.; SABCHAREON, A.; CHONGSUPHAJAISIDDHI, T. \& DRUILHE, P., 1990. Antibody which protect man against. $P$. falciparum blood stages do noit inhibit parasite growth in-vitro but act in cooperation with monocytes. $J$. Exp. Med, 172: 1633-1641.

BOYUM, A., 1968. Isolation of mononuclear cells and granulocytes from human blood. Isolation of mononuclear cells by one centrifugation, and of granulocytes by combining centrifugation and sedimentation at 1 g. Scand. J. Clin. Lab. Invest., 21 (suppl. 97): 77.

CIUCA, M.; BALLIF, \& CHELARESCU-VIERU, M., 1934. Immunity in malaria. Trans. R. Soc. Trop. Med. Hyg., 27: 619-622.

COHEN, S.; MCGREGOR, I.A. \& CARRINGTON, S., 1961. Gamma globulin and acquired immunity to malaria. Nature, 192: 733-737.

DANIELS, C.W., 1901. Notes on "blackwate fever" in British Central Africa. Reponts of the Malaria Committee of the Royal Society. Fifth Series. 44-79.

DRUILHE, P. \& KHUSMITH, S., 1987. Epidemiological correlation between levels of antibodies promoting merozoite phagocytosis of $P$. falciparum and malaria immune status. Inf. Immun., 55: 888-891.

EDOZIEN, J.C.; GILLES, H.M. \& UDEOZO, I.O.K., 1962. Adult and cord-blood gamma-globulin and immunity to malaria in Nigerians. Lancet, Nov. 10: 951-955.

JEFFERIS, R.; REIMER, C.B.; SKVARIL, F.; DE LANGE, G.; LING, N.R.; LOWE, J.; WALKER, M.R.; PHILLIPS, D.J.; ALOISIO, C.H.; WELLS, T.W.; VAERMAN, J.P.; MAGNUSSON, C.G.; KUBAGAWA, H.; COOPER, M.; VARTDAL, F.; VANDVIK, B.; HAAIJMAN, J.J.; MAKELA, O.; SARNESTO, A.; LANDO, Z.; GERGELY, J.; RAFNAVOLGYI, E.; LASZLO, G.; RADL, J. \& MOLINARO, G.A., 1985. Evaluation of monoclonal antibodies having specificity for human $\operatorname{Ig}_{g}$ subclasses: Results of an IUIS/WHO collaborative study. Immunol. Let., 10: 223-248.

KHUSMITH, S. \& DRUILHE, P., 1983. Cooperation between antibodies and monocytes that inhibit invitro proliferation of $P$. falciparum. Inf. Imm., 41:
219-223

LUNEL, F. \& DRUILHE, P., 1989. Effector cells involved in non specific and antibody-dependent mechanisms directed against $P$. falciparum blood stages in vitro. Inf. Imm., S7: 2043-2049.

MARSH, K.; OTOO, L.; CARSON, R.J. \& GREENWOOD, B.M., 1989. Antibodies to blood stage antigens of $P$. falciparum in rural Gambians and their relation to protection against infection. Trans. $R$. Soc. Trop. Med. Hyg., 83: 293-303.

MCGREGOR, I.A.; CARRINGTON, S. \& COHEN, S., 1963. Treatment of East African $P$. falciparum malaria with West African human gamma-globulin. Trans. R. Soc. Trop. Med. Hyg., 57: 170-175.

MORELL, A.; SKVARIL, F.; HIJTZIG, W.H. \& BARANDUN, S., 1972. IgG subclasses: Development of the senum concentrations in normal infants and children. J. Pediatr., 80: 960-964.

REDMOND, W.B., 1941. Immunity to Human malaria; Characterization of immunity p. 231-238. In Forest Ray Noulton (ed.), A Symposium on Human Malaria, Vol. 15. American Association for the advancement of Science, Washington, D.C.

SABCHAREON, A.; BURNOUF, T.; OUATTARA, D. ATTANATH, P.; BOUHAROUN-TAYOUN, H.; CHANTANAVANICH, P.; FOUCAULT, C.; CHONGSUPHAJAISIDDHI, T. \& DRUILHE, $P$. 1991. Parasitological and clinical human response to immunoglobulin administration in falciparum malaria. Am. J. Trop. Med. Hyg., 45; 297-308.

SERGENT, E.D. \& PARROT, L., 1935. L'Immunité, la Prémunition et la Résistance Innée. Archives de I'Institut Pasteur d'Algérie. TXIII, (No. 3): 279-319.

WAHLGREN, M.; BERZINS, K.; PERLMANN, P. \& PERSSON, M., 1983. Characterization of the humoral immune response in $P$. falciparum malaria. Il. IgG subclass levels of anti-P. falciparum antibodies in different sera. Clin Exp. Immunol., 54: 135-142.

WAHLGREN, M.; PERLMANN, H.; BERZINS, K. BJORKMAN, A.; LARSSON, A.; LJUNGSTROM, I.; PATARROYO, M.E. \& PERLMANN, P., 1986. Characterization of the humoral immune response in $P$. falciparum malaria. IIl. Factors influencing the coexpression of antibody isotypes (IgM and IgG-1 to 4). Clin Exp. Immunol., 63: 343-353. 